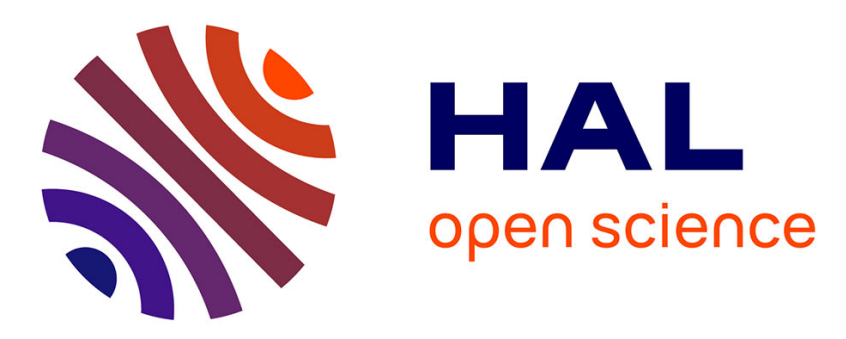

\title{
Barotropic tides of the Southern Indian Ocean and the Amery Ice Shelf cavity
}

\author{
Claire Maraldi, Benjamin Galton-Fenzi, Florent Lyard, Laurent Testut, \\ Richard Coleman
}

\section{- To cite this version:}

Claire Maraldi, Benjamin Galton-Fenzi, Florent Lyard, Laurent Testut, Richard Coleman. Barotropic tides of the Southern Indian Ocean and the Amery Ice Shelf cavity. Geophysical Research Letters, 2007, 34, p. 1-5. ISSN 0094-8276. 10.1029/2007GL030900 . hal-00280378

\section{HAL Id: hal-00280378 https://hal.science/hal-00280378}

Submitted on 6 Apr 2021

HAL is a multi-disciplinary open access archive for the deposit and dissemination of scientific research documents, whether they are published or not. The documents may come from teaching and research institutions in France or abroad, or from public or private research centers.
L'archive ouverte pluridisciplinaire HAL, est destinée au dépôt et à la diffusion de documents scientifiques de niveau recherche, publiés ou non, émanant des établissements d'enseignement et de recherche français ou étrangers, des laboratoires publics ou privés. 


\title{
Barotropic tides of the Southern Indian Ocean and the Amery Ice Shelf cavity
}

\author{
Claire Maraldi, ${ }^{1}$ Benjamin Galton-Fenzi, ${ }^{2,3,4}$ Florent Lyard, ${ }^{1}$ \\ Laurent Testut, ${ }^{1}$ and Richard Coleman ${ }^{2,3,4}$ \\ Received 8 June 2007; revised 23 July 2007; accepted 2 August 2007; published 21 September 2007.
}

[1] The 8 main tidal constituents were computed using a finite element, hydrodynamic ocean tide model over the South Indian Ocean region. The discretization of the domain is of the order of $100 \mathrm{~km}$ over the deep ocean and a few hundred meters near the coast. Such refinement in the grid resolution enables wave propagation and damping on the continental shelves to be solved correctly. The model used the GEBCO 1-minute global bathymetric grid which was improved with updated topographic data. The model solutions show good agreement with in-situ observations and Topex-Poseidon altimeter measurements and are significantly better than previously published solutions. We obtain a combined standard deviation of $1.4 \mathrm{~cm}$ for differences of our new regional model against independent observations compared to about $2.5 \mathrm{~cm}$ for the other tide models. The greatest improvements are found around the Kerguelen Islands, around Antarctica and beneath the Amery Ice Shelf and can be explained by the high grid resolution used and the particular attention given to the accuracy of the bathymetry in those regions. Citation: Maraldi, C., B. GaltonFenzi, F. Lyard, L. Testut, and R. Coleman (2007), Barotropic tides of the Southern Indian Ocean and the Amery Ice Shelf cavity, Geophys. Res. Lett., 34, L18602, doi:10.1029/2007GL030900.

\section{Introduction}

[2] The ocean tide is one of the major components of the sea surface height ( $\mathrm{SSH}$ ) variability. The necessity to remove their contribution from satellite altimetric data led to a huge improvement of the global ocean tide models in the 1990's. Most of the tidal models are now consistent in the deep ocean at a centimeter level [Le Provost, 2001]. The new challenge for new tidal models is to provide accurate solutions in shelf and coastal areas and at high latitudes where strong discrepancies between models still remain [Ray, 2007]. It is critical to have accurate coastal tidal solutions for areas, such as assessing the impact of tidal dissipation and internal waves on tidal dynamics, looking at evidence for tidal modulation of large ice streams [Binschadler et al., 2003]. Indeed, the increasing demand on coastal altimetry products and the development of high resolution ocean regional models requires a more accurate knowledge of tides at the coast

\footnotetext{
${ }^{1}$ LEGOS, Toulouse, France.

${ }^{2}$ Centre for Marine Science, University of Tasmania, Hobart, Tasmania, Australia.

${ }^{3}$ CSIRO Marine and Atmospheric Research, Hobart, Tasmania, Australia.

${ }^{4}$ Antarctic Climate and Ecosystems CRC, Hobart, Tasmania, Australia.
}

Copyright 2007 by the American Geophysical Union. 0094-8276/07/2007GL030900 and on the shelves. Recent global (FES2004, TPXO7.0) and Antarctic (CATS02.01, CADA00.10) tidal models that use or assimilate in-situ data and altimetric information have improved our knowledge of the tidal solutions in the Southern Ocean. However, their use is limited for several reasons: i) their horizontal spatial resolution is too low to adequately represent tides in coastal regions where tides are complicated, ii) the $66^{\circ} \mathrm{S}$ latitudinal cut-off of the TopexPoseidon (T/P) satellite dramatically reduces the number of data that are available for the assimilation around Antarctica, iii) the accuracy of tidal models are limited by the lack of insitu measurements in the Southern Ocean and along the Antarctic margin. Thus, it is necessary to create high resolution tidal solutions, that use a purely hydrodynamic modelling approach, to extend empirical tidal models beyond the $\mathrm{T} / \mathrm{P}$ satellite sampling area and provide accurate tidal solutions in regions where few tidal records are available.

[3] Our approach is to test the ability of a high resolution, purely hydrodynamic tidal model in the Southern Indian Ocean, which is a region where many (if not all) of the above cited limiting factors are present. Indeed the model domain, which covers a great part of the South Indian Ocean from $35^{\circ}$ down to the Antarctic continent, contains areas where the tides are known to be particularly complex. The model domain, between longitudes $43^{\circ}$ and $90^{\circ}$, includes the Kerguelen Plateau which acts as a topographic barrier in the Southern Ocean, the rugged Kerguelen Islands on a shallow circular rise, and the Amery Ice Shelf (AIS), the largest ice shelf in East Antarctica. Tide modelling is especially important as there is likely to be high dissipation of tidal energy over the topographic features [Egbert and Ray, 2000, 2003]. Tides also likely have a role in the loss of shelf ice at the front of ice shelves, especially during the calving process and are suggested to be important in basal melting processes [Padman et al., 2003].

[4] Here we begin by describing the finite element model and the input parameters used for the simulation; particular attention is given to the bathymetry used. Then, we review the available $\mathrm{SSH}$ data in the South Indian Ocean and present the ocean tide models used for the comparisons. Finally, we discuss the outputs and performances of the new tide model.

\section{Model Design}

\subsection{Model Description}

[5] MOG2D (2D Gravity waves model) is a barotropic, time-stepping and non-linear model. Derived from Lynch and Gray [1979], MOG2D computes the sea level variations and mean currents due to wind forcing and tidal forcing by solving the shallow water and momentum 


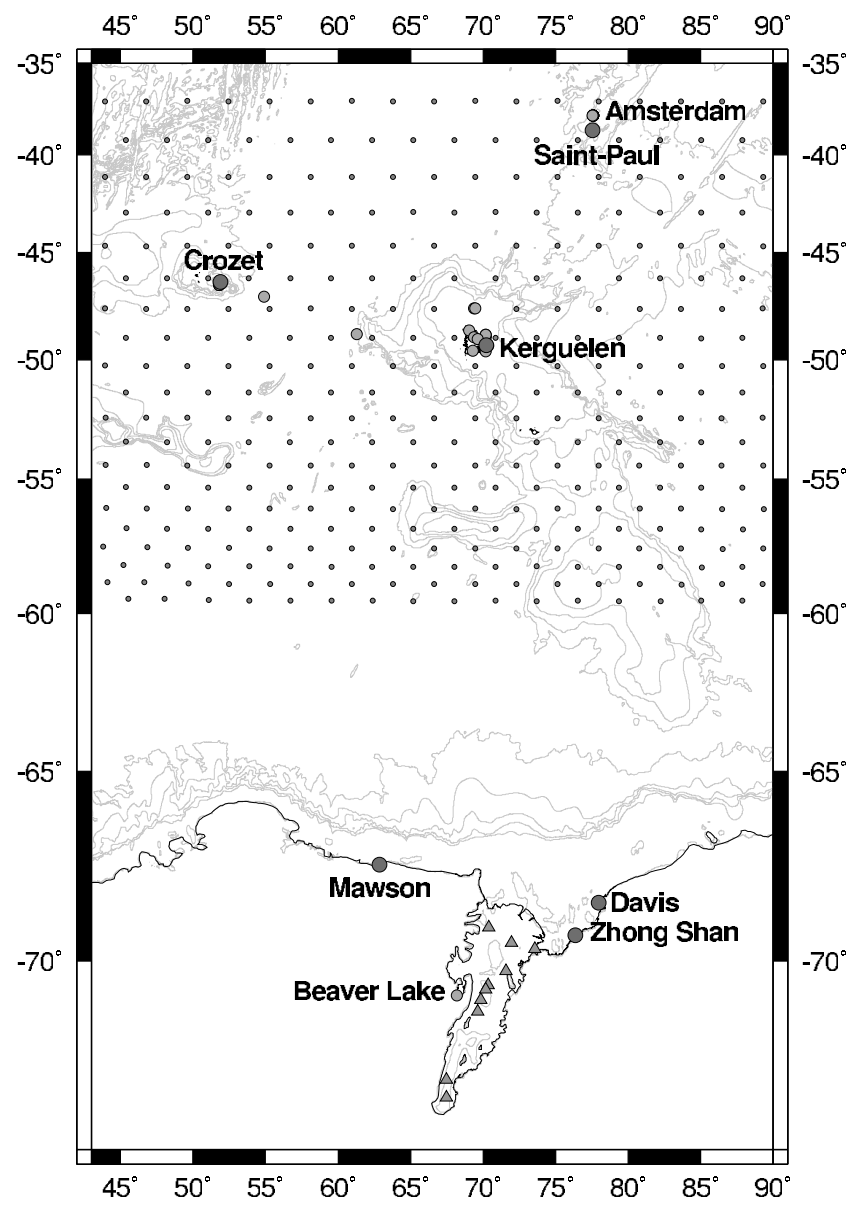

Figure 1. In-situ data and $\mathrm{T} / \mathrm{P}$ crossover points used for the validation. The CTG positions are represented by dark circles, the moorings by clear circles, the GPS by triangles and the T/P crossovers by dark dots.

equations on a finite element (FE) mesh. This space discretization method allows the mesh to be larger in the deep ocean and the resolution to be increased in coastal regions and regions with strong topographic gradients, enabling good resolution of gravity waves. The criterion for the spatial resolution is directly linked with the bathymetry, its gradient and the wavelength of the waves to be solved [Le Provost and Vincent, 1986]. The FE mesh in the model covers the southern area of the Indian Ocean with a grid size ranging from a few kilometers or less along the island coasts, the Amery Ice Shelf grounding line, the Kerguelen plateau break and the Antarctic shelf break up to $100 \mathrm{~km}$ in the deep ocean. Figure 1 shows a map of the mesh grid around the Kerguelen Islands, the horizontal grid length is only $400 \mathrm{~m}$ in Morbihan Bay, the principal bay of the Kerguelen Islands.

[6] Seasonal effects and tidal flexure at the ice shelf margins are not included in this model. We consider that ice floating on the ocean only acts to increase the frictional coefficient; the ice coverage is represented by a doubling of the bottom friction coefficient [Kowalik, 1981; MacAyeal, 1984]. Two tidal simulations have been done in order to investigate the sensitivity of the model to ice cover. In the first simulation (simulation 1) the doubling of the bottom friction coefficient is restricted to the AIS region, following the studies beneath other Antarctic ice shelves [MacAyeal, 1984]. In the second simulation (simulation 2), we have increased the area where the friction coefficient is doubled to include sea ice. As the sea ice cover varies seasonally, we have averaged its distribution over the model run period using the NSIDC data [Comiso, 2005]; the friction coefficient has been weighted according to the presence of sea ice. The shallow water equations are solved using the value of the water column thickness, which corresponds to the water depth for the open ocean. Thus, the submerged ice thickness should be subtracted from the bathymetry in ice-covered regions [Genco et al., 1994]. This correction is insignificant for seasonal sea ice as the few meters of ice thickness is negligible compared to the ocean depth. However, it becomes significant for the permanent AIS where the thickness can reach several hundred meters at the ice shelf front and up to several kilometers at the southern grounding zone [Fricker et al., 2002; McMahon and Lackie, 2006]. For the AIS region, the bathymetry has been replaced by the water column thickness.

[7] Our tide model simulates the four semi diurnal $\left(M_{2}\right.$, $\left.S_{2}, K_{2}, N_{2}\right)$ and four diurnal $\left(K_{1}, O_{1}, P_{1}, Q_{1}\right)$ tidal constituents. The simulations are run for one year so that each constituent can be clearly separated when computing the harmonic analysis. The tidal elevation prescribed at the open ocean boundaries and the tidal loading effects are extracted from the FES2004 solution.

\subsection{Input Parameters}

\subsubsection{Coastline}

[8] One of the major sources of error in ocean modelling around Antarctica is the inaccurate definition of the coastlines and grounding lines and the shape of the cavity geometry beneath ice shelves. A recent study of the tides of the Ross Ice Shelf cavity has shown that the tidal solutions can change significantly when the grounding zone location is modified [Padman et al., 2003]. As the sub-ice cavity geometry is an important parameter to improve tide modelling, the AIS cavity has been recently updated by B. Galton-Fenzi et al. (The geometry of the cavity beneath the Amery Ice Shelf, East Antarctica, manuscript in preparation, 2007, hereinafter referred to as Galton-Fenzi et al., manuscript in preparation, 2007) to match all the available data, including seismic profiles [Tassell, 2004; McMahon and Lackie, 2006] and GPS data [Zhang and Andersen, 2006]. Additional modifications have been made to the more recent redefinition of the AIS grounding line [Giovanni et al., 2007] to account for new in-situ and satellite data.

\subsubsection{Bottom Topography}

[9] The definition of the bottom topography is a critical aspect of the modelling and its quality has a direct impact on the model results. The bathymetry used here is based on the GEBCO 1-minute global bathymetric grid. These data are not sufficiently accurate in the shallow water regions and beneath the ice shelves around Antarctica, some modifications have been made that use several recent sources of topographic data.

[10] The depths are shallow around the Kerguelen Islands and topographic inaccuracies have a considerable impact on the model output quality. The bathymetry has been locally 


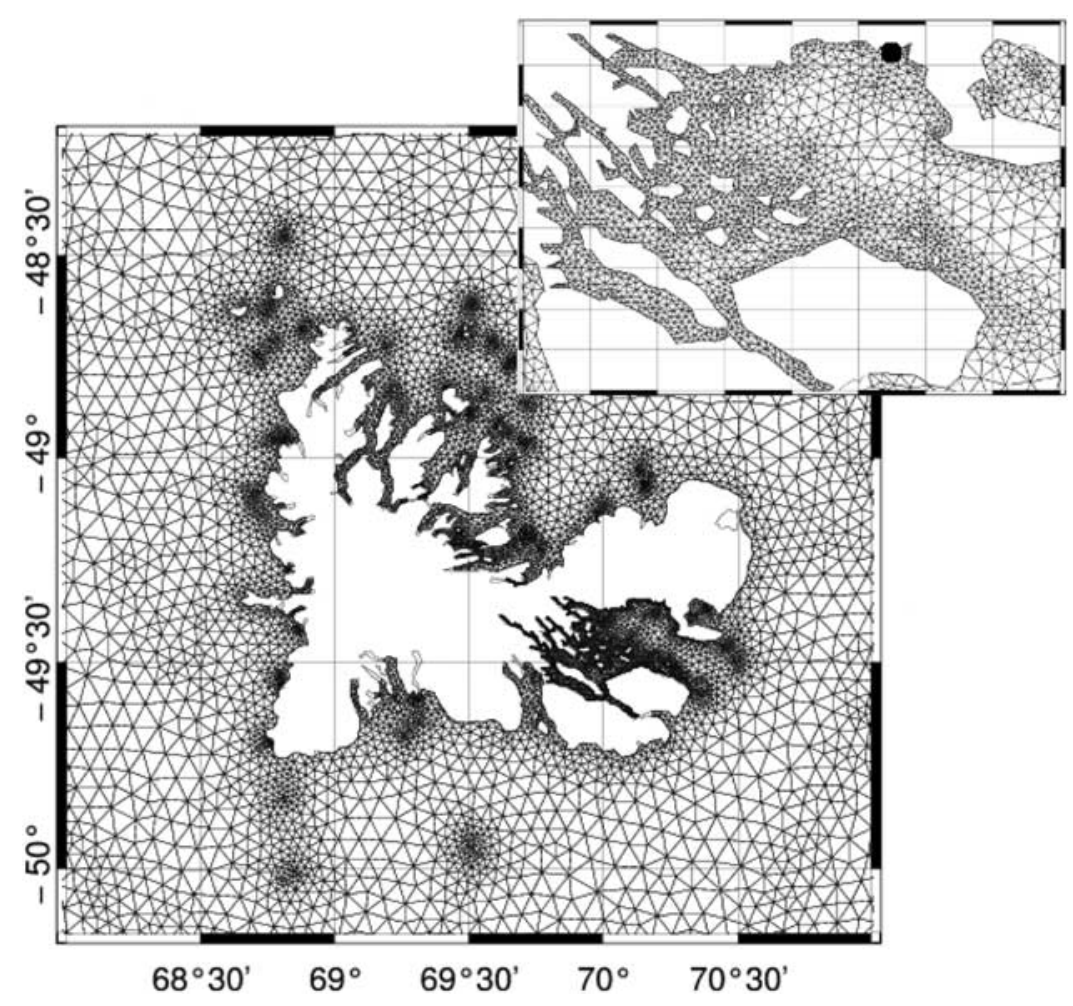

Figure 2. Finite element mesh around the Kerguelen Islands. Zoom of the mesh in Morbihan Bay and position of the Kerguelen coastal tide gauge.

regenerated using French National Marine (SHOM) topographic data.

[11] Our ability to model the tides beneath the AIS also depends on an accurate knowledge of the water column thickness inside the cavity. The scarce topographic data in this region have been used to regrid a bathymetry consistent with the new grounding line definition and consistent with GPS data which also included new bathymetry in Prydz Bay (Galton-Fenzi et al., manuscript in preparation, 2007).

\section{Data}

\subsection{Validation Data Set}

[12] The data set around the French Southern and Antarctic Lands has been extracted from the ROSAME network (3 coastal tide gauges (CTG) and 25 one-year mooring records) and from the SHOM data (6 moorings). We have also used two benthic tide gauges situated between the Kerguelen and Crozet Islands [Rietbroek et al., 2006]. On the Antarctic coast we have used tide gauge (TG) data taken at China's Zhong Shan station (one CTG), Australia's Davis and Mawson stations (CTGs) and Beaver Lake (TG), which was provided by the Australian Antarctic Data Centre. These data are supplemented with elevation data that were measured using the Global Positioning System (GPS) at 10 different sites on the AIS.

[13] The Topex-Poseidon (T/P) sea level anomalies computed at the crossovers were also used for the comparisons with the model outputs. In addition to classical geophysical corrections, a specific data processing technique has been used for the inverse barometer correction [Carrère and Lyard, 2003] which includes wind effects as well as the static response of the ocean to changes in atmospheric pressure. Sea level heights were corrected from the mean sea surface (MSS) computed at CLS [CLS, 2004] in the deep ocean and a new MSS was computed using a local inverse method in regions of high geoid gradients. The coastal altimetric data processing used here [Vignudelli et al., 2005] has allowed us to use a high quality data set in the open ocean and in coastal regions. Moreover, all the T/P crossover points located south of $60^{\circ}$ have been removed from the altimetric data set as they have likely been contaminated by the elevation of the sea ice. The in-situ data sites and the $\mathrm{T} / \mathrm{P}$ crossover points are presented in Figure 2.

[14] Both data sets have been divided into two regions to simplify comparisons with the Antarctic tide models as they do not cover the entire region of study.

\subsection{Ocean Tide Models}

[15] Following the study of King and Padman [2005] we have chosen two global (FES2004, TPXO7.0) and two Antarctic (CADA00.10, CATS02.01) tide models for the comparisons with our new tide model. FES2004 [Lyard et al., 2006] is the latest version of the Finite Element Solution [Le Provost et al., 1998]. It is a global tide solution obtained by computing the spectral model from Le Provost et al. [1978] and data assimilation on a FE mesh. The solution assimilates T/P, ERS and four tide gauges around Antarctica. TPXO7.0 is a global model of ocean tides on a $0.25^{\circ} \times$ $0.25^{\circ}$ grid assimilating T/P and Jason data in the Laplace tidal equations [Egbert et al., 1994]. CADA00.10 and CATS02.01 [Padman et al., 2002] are interpolated onto a grid with a resolution of $0.25^{\circ}$ latitude and $0.083^{\circ}$ longitude. 
Table 1. RMS $\sigma, \mathrm{cm}$, for Each Model and for Different Data Sets ${ }^{\mathrm{a}}$

\begin{tabular}{lccccc}
\hline \multicolumn{1}{c}{$M_{2}$} & MOG2D & FES & TPXO & CADA & CATS \\
\hline TP all & 0.6 & 0.6 & 0.6 & & \\
TP S58 & 0.5 & 0.5 & 0.5 & 0.5 & 0.5 \\
In situ all & 0.8 & 1.3 & 1.2 & & \\
In situ N58 & 0.7 & 1.2 & 1.2 & & \\
In situ S58 & 0.9 & 2.3 & 1.3 & 1.1 & 1.3 \\
$S_{2}$ & MOG2D & FES & TPXO & CADA & CATS \\
TP all & 0.6 & 0.6 & 0.6 & & \\
TP S58 & 0.5 & 0.5 & 0.5 & 0.5 & 0.5 \\
In situ all & 0.7 & 1.2 & 1.0 & & \\
In situ N58 & 0.5 & 0.6 & 0.8 & & \\
In situ S58 & 1.0 & 2.2 & 1.5 & 1.3 & 1.5 \\
$K_{1}$ & MOG2D & FES & TPXO & CADA & CATS \\
TP all & 0.7 & 0.7 & 0.7 & & \\
TP S58 & 0.7 & 0.6 & 0.7 & 0.7 & 0.7 \\
In situ all & 0.7 & 1.2 & 0.8 & & \\
In situ N58 & 0.5 & 0.5 & 0.6 & & \\
In situ S58 & 1.0 & 2.2 & 1.2 & 1.0 & 1.3 \\
$O_{1}$ & MOG2D & FES & TPXO & CADA & CATS \\
TP all & 0.6 & 0.6 & 0.6 & & \\
TP S58 & 0.6 & 0.5 & 0.5 & 0.5 & 0.5 \\
In situ all & 0.7 & 1.2 & 1.2 & & \\
In situ N58 & 0.5 & 0.5 & 0.6 & & \\
In situ S58 & 0.9 & 2.1 & 1.1 & 1.0 & 1.2 \\
\hline
\end{tabular}

${ }^{\mathrm{a}}$ The results are presented for the four main tidal constituents. TP all: 331 TP crossover points situated between $35^{\circ} \mathrm{S}$ and $60^{\circ}$, TP S58 : $60 \mathrm{TP}$ crossovers situated between $58^{\circ}$ and $60^{\circ}$. In situ all: all the in situ data (50 sites). In situ $\mathrm{N}^{\circ} 8^{\circ}$ : in situ data up $58^{\circ}\left(36\right.$ sites). In situ $\mathrm{S} 58^{\circ}$ : in situ data up $58^{\circ}(14$ sites $)$.

Both are circum-Antarctic models that include ocean ice shelf cavities and are forced at the open boundary $\left(58^{\circ} \mathrm{S}\right)$ by TPXO6.2. Furthermore, CADA00.10 assimilates T/P sea surface heights, tide gauge data and GPS measurements made on ice shelves.

\section{Model Results}

[16] For each model, the tidal solutions have been compared to the different validation data sets. To do this comparison, we have computed the root-mean-square (RMS) for each constituent using:

$$
\sigma=\sqrt{\frac{1}{2 N} \sum_{I=1}^{N}\left(z_{i, \text { observation }}-z_{i, \text { model }}\right)^{2}}
$$

As the RMS difference is computed from the complex modulus $z_{c}=A_{c}\left(\cos \left(\phi_{c}\right)+i \sin \left(\phi_{c}\right)\right)$ at each location $i$, it allows us to consider both the amplitude $A_{c}$ and the phase $\phi_{c}$ of each tidal constituent.

[17] The best comparison (smallest $\Sigma$ ) was obtained with simulation 1 which corresponds to a friction coefficient that has only been doubled beneath the AIS ice shelf - consistent with previous studies [Lyard, 1997].

[18] We focus on the four main tidal constituents $\left(M_{2}, S_{2}\right.$, $\left.K_{1}, O_{1}\right)$ as they dominate the tide height variability. Table 1 lists the values of $\sigma$ for comparisons with the in-situ and altimetric data for our regional model, the two global models and the two circum-Antarctic models. The standard deviation values for the T/P data sets are less than $1 \mathrm{~cm}$ per constituent for each tidal solution. It shows that all the models are very accurate in the deep ocean. This is mainly due to the T/P data assimilation for the global and Antarctic models. It also demonstrates the accuracy of our dynamiconly model in the open ocean.

[19] The standard deviations computed for the in-situ data are also of the order of $1 \mathrm{~cm}$ for MOG2D but are larger for the other models; however, the quality of the results is variable. In the northern part of our model domain (to $58^{\circ} \mathrm{S}$ ), the results of the models are relatively coherent with data observations in most places. The larger differences are around the Kerguelen Islands, largely because the coastal tide gauge and several moorings are located in island bays where local effects, such as shelf resonance and harbor seiching, dominate. In our modelling we have used a high resolution mesh to best represent the bay geometry and we have given particular attention to the bathymetry around the Kerguelen Islands. The combination of these parameters has allowed us to obtain very accurate tidal solutions in this region. When computing the combination of the complex errors for the four main constituents and all the data situated north to $58^{\circ} \mathrm{S}$, the value obtained for our regional model is $11 \%$ better than for the next most accurate model in this region, FES2004, which assimilates the Kerguelen CTG data records.

[20] Comparisons with the Antarctic data sets show that MOG2D is again the most accurate model. Note that the standard deviation per constituent is larger than for the South Indian Ocean data sets. The model shows very good agreement with the three CTGs and GPS situated in the northern region of the AIS (the complex RMS is about $1 \mathrm{~cm}$ ) and relatively good consistency with the GPS measurements located in the southern region (the complex RMS is about $3 \mathrm{~cm}$ ). The largest discrepancy appears with the Beaver Lake TG, situated to the west but joined to the AIS. At this tide gauge location, the amplitude of the model and the data differs slightly but not enough to represent the $20^{\circ}$ phase lag for the semi-diurnal constituents. This explains the large standard deviation obtained for the $M_{2}$ and $S_{2}$ constituents $\left(\left|z_{\text {obs }}-z_{\text {model }}\right|=7.2 \mathrm{~cm}\right.$ for $M_{2}$ at Beaver Lake). This phase lag is also found with the other model comparisons and also in regional barotropic model of tides beneath the AIS [Hemer et al., 2006]. The inlet connection between Beaver Lake and the ocean beneath the AIS was modified, based on Synthetic Aperture Radar imagery which showed a grounded region near the glacial inlet. The updated inlet and lake geometry accounted for the cause of the phase lag, however, the solution is very sensitive to these model dimensions (B. Galton-Fenzi, personal communication, 2007). The level of agreement of our regional model is $16 \%$ better than CADA, the next most accurate model, which assimilates the three TG sites and 4 GPS sites situated in the northern part of the AIS. Furthermore, our model is in better agreement with the in-situ data than the most recent tidal model developed beneath the AIS [Hemer et al., 2006]. These improvements are mostly due to the well defined cavity geometry in this region, developed by adjusting unknown regions of the AIS cavity to better agree with GPS data using MOD2D (Galton-Fenzi et al., manuscript in preparation, 2007).

\section{Conclusion}

[21] Comparisons with in-situ and $\mathrm{T} / \mathrm{P}$ altimetric data have shown that our new regional barotropic tide model 
performs significantly better than the present global models and Antarctic models including those that assimilate data in the South Indian Ocean. The results of the validation are equivalent in the deep ocean for all of the models but the high finite element resolution used here has allowed the tides to be better represented in the coastal regions. The $2 \mathrm{~cm}$ standard deviation difference beneath the AIS is still much larger than the $1 \mathrm{~cm}$ obtained in the open ocean but it accounts for a significant improvement in the tidal solutions in this region.

[22] In addition, our tidal solutions have been obtained by using a purely hydrodynamic model. Thus, we can reasonably expect accurate results for regions well away from the data used for the comparisons, which is not the case for the models that assimilate those data. The level of accuracy reached, both in the deep ocean as well as in coastal areas, demonstrates the ability of shallow water, finite element models to increase our knowledge of tides given accurate high resolution bathymetry and coastline definition.

[23] Our new model approach can now be used to better correct the altimetric data measurements from the tide heights in the South Indian Ocean, either in the deep ocean or at the coast, where former corrections are known to be poor. Moreover this new regional tidal solution can be useful for different kinds of studies. For example, the tidal currents and their residual currents could be used to infer the potential production of internal waves, which is vital for projects such as KEOPS (KErguelen: compared study of the Ocean and Plateau in Surface water) [Blain et al., 2007], studying the effect of natural iron fertilization of the ocean near the Kerguelen plateau. The improvement reached by the model, combined with its high spatial resolution in shelf regions, will allow us to better study the interaction between tides and the ice-shelf dynamics in the region.

[24] Acknowledgments. TG data was courtesy of the Australian Antarctic Data Centre and BoM National Tidal Centre. Pascal Legrand and Rietbroek Roelof provided data from two benthic tidal sites for the study region. Neal Young is thanked for supplying the updated grounding line position for the AIS, Helen Fricker for providing ice thickness maps for the AIS, Rachael Hurd for doing the AIS GPS data processing and John Hunter for comments.

\section{References}

Binschadler, R., M. A. King, R. B. Alley, S. Ananadakrishnan, and L. Padman (2003), Tidally controlled stick-slip discharge of a West Antarctic ice stream, Science, 301(5636), 1087-1089.

Blain, S., G. Sarthou, P. Laan, D. Amouroux, D. Point, and A. Barats (2007), Distributions of dissolved iron and manganese during the natural iron fertilisation experiment, Deep Sea Res., in press.

Carrère, L., and F. Lyard (2003), Modeling the barotropic response of the global ocean to atmospheric wind and pressure: Comparisons with observations, Geophys. Res. Lett., 30(6), 1275, doi:10.1029/ 2002 GL016473.

CLS (2004), SSALTO/DUACS User Handbook, Collecte Localisation Satellites Edition, Ramonville Saint-Agne, France.

Comiso, J. (2005), Bootstrap sea ice concentrations for NIMBUS-7 SMMR and DMSP SSM/I, technical report, Natl. Snow and Ice Data Cent., Boulder, Colo.
Egbert, G., and R. Ray (2000), Significant dissipation of tidal energy in the deep ocean inferred from satellite altimeter data, Nature, 405, 775-778.

Egbert, G. D., and R. D. Ray (2003), Semi-diurnal and diurnal tidal dissipation from Topex/Poseidon altimetry, Geophys. Res. Lett., 30(17), 1907, doi:10.1029/2003GL017676.

Egbert, G., A. Bennett, and M. Foreman (1994), TOPEX/Poseidon tides estimated using a global inverse model, J. Geophys. Res., 99(C12), $821-$ 852.

Fricker, H. A., I. Allison, M. Craven, G. Hyland, A. Ruddell, N. Young, R. Coleman, M. King, K. Krebs, and S. Popov (2002), Redefinition of the Amery Ice Shelf, East Antarctica, grounding zone, J. Geophys. Res., 107(B5), 2092, doi:10.1029/2001JB000383.

Giovanna, L., I. Allison, and N. Young (2007), Determining the coastline of the Antarctic using remote sensing techniques, Polar Geogr., in press.

Genco, M. L., C. Le Provost, and F. Lyard (1994), The oceanic tides in the South Atlantic Ocean, Ann. Geophys., 12, 868-886.

Hemer, M. A., J. R. Hunter, and R. Coleman (2006), Barotropic tides beneath the Amery Ice Shelf, J. Geophys. Res., 111, C11008, doi:10.1029/ 2006JC003622.

King, M., and L. Padman (2005), Accuracy assessment of ocean tide models around Antarctica, Geophys. Res. Lett., 32, L23608, doi:10.1029/ 2005GL023901.

Kowalik, Z. (1981), A study of the M2 tide in the ice-covered Arctic, Model. Ident. Control, 2(4), 201-223.

Le Provost, C. (2001), Ocean tides, in Satellite Altimetry and Earth Sciences, edited by L. L. Fu and A. Cazenave, chap. 6, Academic, San Diego, Calif.

Le Provost, C., and A. Poncet (1978), Finite element method for spectral modelling of tides, Int. J. Numer. Methods Eng., 12, 853-871.

Le Provost, C., and P. Vincent (1986), Some tests of precision for a finite element model of ocean tides, J. Comput. Phys., 65, 273-291.

Le Provost, C., F. Lyard, J. M. Molines, M. L. Genco, and F. Rabilloud (1998), A hydrodynamic ocean tide model improved by assimilating a satellite altimeter-derived data set, J. Geophys. Res., 103, 5513-5530.

Lyard, F. (1997), The tides in the Arctic Ocean from a finite element model, J. Geophys. Res., 15, 611-638.

Lyard, F., F. Lefebre, and T. Letellier (2006), Modelling the global ocean tides: Modern insights from FES2004, Ocean Dyn., 56, 394-415.

Lynch, D. R., and W. G. Gray (1979), A wave equation model for finite element tidal computations, Comput. Fluids, 7, 207-228.

MacAyeal, D. R. (1984), Numerical simulations of the Ross Sea Tides, J. Geophys. Res., 89, 607-615.

McMahon, K. L., and M. A. Lackie (2006), Seismic reflection studies of the Amery Ice Shelf, East Antarctica: Delineating meteoric and marine ice, Geophys. J. Int., 166, 757-766.

Padman, L., H. A. Fricker, R. Coleman, S. Howard, and L. Erofeeva (2002), A new tide model for the Antarctic ice shelves and seas, Ann. Glaciol., 34, 247-254.

Padman, L., S. Erofeeva, and I. Joughin (2003), Tides of the Ross Sea and Ross Ice Shelf cavity, Antarct. Sci., 15, 31-40.

Ray, R. D. (2007), Tidal analysis experiment with Sun-synchronous satellite altimeter data, J. Geodyn., 81, 247-257.

Rietbroek, R., P. LeGrand, B. Wouters, J.-M. Lemoine, G. Ramillien, and C. W. Hughes (2006), Comparison of in situ bottom pressure data with GRACE gravimetry in the Crozet-Kerguelen region, Geophys. Res. Lett., 33, L21601, doi:10.1029/2006GL027452.

Tassell, H. (2004), Seismic investigation into the ice thickness and seabed topography beneath the Amery Ice Shelf, East Antarctica, thesis, pp. 134, Univ. of Tasmania, Hobart, Tasmania, Australia.

Vignudelli, S., H. M. Snaith, F. Lyard, P. Cipollini, F. Venuti, F. Birol, J. Bouffard, and L. Roblou (2005), Improved satellite altimetry in coasta systems: Case study of the Corsica Channel (Mediterranean Sea), Geophys. Res. Lett., 32, L07608, doi:10.1029/2005GL022602.

Zhang, X., and O. B. Andersen (2006), Surface ice flow velocity and tide retrieval of the Amery ice shelf using precise point positioning, J. Geodyn., $80,171-176$.

R. Coleman and B. Galton-Fenzi, Centre for Marine Science, University of Tasmania, Private Bag 78, TAS 7001 Hobart, Australia.

F. Lyard, C. Maraldi, and L. Testut, LEGOS, 14 av. Edouard Belin, F-31400 Toulouse, France. 